\title{
Patterns of lymphadenopathy on fine needle aspiration cytology in eastern Nepal
}

\author{
Mainali $\mathrm{N}^{1}$, Suwal RB ${ }^{2}$ \\ ${ }^{\prime}$ Department of Pathology, Nobel Medical college teaching hospital \& research center, Biratnagar, Nepal \\ ${ }^{2}$ Department of Otorhinolaryngolgy, Nobel Medical college teaching hospital \& research center, Biratnagar, Nepal
}

\section{Keywords: \\ FNAC; \\ Lymphadenopathy; \\ Tuberculosis; \\ Metastasis.}

\begin{abstract}
BACKGROUND: Lymphadenopathy is a commonly encountered clinical problem. Fine needle aspiration cytology offers the alternative of an immediate, preliminary, although not always specific diagnosis with little trauma and cost, thus providing ample information for further management and reduce the amount of open biopsy.
\end{abstract}

MATERIAL AND METHODS: FNAC was performed using 21 gauge needle attached with $10 \mathrm{ml}$ disposable needle. Slides were prepared, two were air dried and stained with field stain where as two were fixed in ethanol and was stained with PAP stain. One slide was stained with Ziehl-Neelson stain. Field and PAP stained slide were reviewed and diagnosed by Pathologist.

RESULT: Out of the 225 patients, reactive lymphadenitis was the most common diagnosis (54.2\%), followed by tubercular lymphadenitis (33.44\%). Among the age group percentage of tubercular lymphadenitis was more in 21-30 years of age. Majority of the metastatic carcinoma was in cervical region, comprising mainly squamous cell carcinoma.

CONCLUSION: Reactive lymphadenitis was the most common cause of lymphadenopathy especially in case of children. In case of older population, definite pathology for lymph node enlargement was found in most of the cases. Hence FNAC is warranted in lymphadenopathy, as it is simple yet of great diagnostic value.

\section{INTRODUCTION}

Lymphadenopathy is a commonly encountered clinical problem, cause of which can be various. Excisional Biopsy

\footnotetext{
Correspondence:

Dr. Nirajan Mainali, MBBS, MD

Lecturer, Department of Pathology

Nobel Medical college teaching hospital \& research center.

Email:mainali_nirajan@hotmail.com
}

of cervical lymph node is relatively easy procedure, however it requires anesthesia with risk to injured vitals surrounding structure. Fine needle aspiration cytology (FNAC) offers the alternative of an immediate, preliminary, although not always specific diagnosis with little trauma and cost, thus providing ample information for further management and reduce the amount of open biopsy. ${ }^{1}$

First FNAC was done in 1904 by two British marine 
officers, Captain E.D.W. Greig and Lieutenant A.C.H. Gray who reported their findings on the aspiration of lymph nodes in sleeping sickness. The first uses of lymph node FNA in the diagnosis of tumors occurred in 1914 by an English physician, Gordon R. Ward who was able to diagnose lymphomas by this method. In 1921, Dr. C.G. Guthrie, head of the department of Clinical Pathology at the Johns Hopkins Hospital, successfully made the diagnosis of Hodgkin lymphoma and the patient received treatment based solely on that diagnostic procedure.

The present study is undertaken to know the cytomorphological pattern of lymphadenopathy in the department of Pathology in Nobel medical college hospital and research center.

\section{MATERIALS AND METHODS}

The present study was carried out in the department of pathology, Nobel medical college from the period of 2013 july $1^{\text {st }}-2014$ December $31^{\text {st }}$ (18 months). Permission from Ethical committee was taken and consent form was taken from the patient prior to performing procedure; after explaining the procedure. FNAC was performed using 21 gauge needle attached with $10 \mathrm{ml}$ disposable needle. Five slides were prepared from each FNAC, two were air dried and stained with field stain where as two were fixed in ethanol and was stained with PAP stain. One slide was stained with Ziehl-Neelson stain.

Field and PAP stained slide were observed in 4x,10x and 40x objectivelens, whereas Ziehl-Neelson stained slide were observed in 100x oil immersion objective lens. Data were analyzed using SPSS 15.

\section{RESULTS}

Out of the 225 patients, most of the patient presented with lymphadenopathy were younger age group. More than $80 \%$ of the patients were less than 30 years of age. (Table 1). Out of these 225 patients; reactive lymphadenitis was the most common diagnosis $(54.2 \%)$, followed by tubercular lymphadenitis(33.44\%). A total of 13 cases (5.78\%) were of lymphoma, which was seen in almost all age group. A single case of Rosai Dorfman disease was seen in a cervical region on a patient of age 1 years. (Table 2)
Majority of the metastatic carcinoma was in cervical region, comprising mainly squamous cell carcinoma. Single case in that region was of papillary carcinoma. Intra-abdominal lymph node predominance of tuberculosis. One case of seminoma (para aortic region) and three cases of adenocarcinoma (mesenteric lymph node) was identified as metastasis in that region.

\section{DISCUSSION}

Modalities of diagnostic tools like FNAC is of great tool in the country like Nepal especially in the rural areas where people are less educated and are scared to do biopsy examination, both financially and physically. Due to the quick delivery of the report, people collect report which in contrast to biopsies report are forgotten to collect, hence interfering the treatment.

During this study period total of 225 FNACs were performed in the department of pathology in Nobel Medical College. Cervical lymphadenopathy was the most common site involved in our study. It was similar to the study done by others. ${ }^{3-7}$

The most common cytological diagnosis was reactive lymphadenitis, similar to the study done by hirachand et $\mathrm{al}^{4}$ and Egas et $\mathrm{al}^{8}$ Tubercular lymphadenitis was the most common diagnosis in the study done by Ruchl et $\mathrm{al}^{3}$, Mandakini et $\mathrm{al}^{5}$ and Haque et al. ${ }^{6}$

The most common age group was 0-10 years in our study. It was similar to the study done by ruche et $\mathrm{al}^{3}$. In the study done by mandakini et $\mathrm{al}^{5}$ and shrestha et $\mathrm{al}^{9}, 21-30$ years of age was the most common age group.

Cervical region was the most common site for metastasis with Squamous cell carcinoma being the most common metastatic deposits to the node. This

Table 2: Cytologic diagnosis of 225 cases of lymphadenopathy

\begin{tabular}{lcc}
\hline \multicolumn{1}{c}{ Diagnosis } & No. of cases & Percentage \\
\hline Reactive lymphadenitis & 122 & 54.2 \\
Tubercular lymphadenitis & 73 & 32.44 \\
Lymphoma & 13 & 5.78 \\
Metastatic carcinoma' & 16 & 7.11 \\
Rosai Dorfman Disease & 01 & 0.45
\end{tabular}

Table 1 :Age distribution of the patients with lymphadenopathy

\begin{tabular}{|c|c|c|c|c|c|}
\hline Age & Reactive & Tubercular & Lymphoma & Metastatic c & RS disease \\
\hline $0-10$ & 63 & 26 & 02 & 00 & 00 \\
\hline $11-20$ & 26 & 15 & 04 & 00 & 01 \\
\hline $21-30$ & 21 & 16 & 03 & 03 & 00 \\
\hline $31-40$ & 06 & 7 & 04 & 04 & 00 \\
\hline $41-50$ & 05 & 6 & 00 & 04 & 00 \\
\hline $51+$ & 01 & 3 & 00 & 05 & 00 \\
\hline
\end{tabular}


result was similar to the study done by Ruchee et $\mathrm{al}^{3}$, Engzell et $\mathrm{al}^{10}$, Hirachand et $\mathrm{al}^{4}$ and Hajdu et $\mathrm{al}^{11}$.

\section{CONCLUSION}

Reactive lymphadenitis was the most common cause of lymphadenopathy especially in case of children. In case of older population, definite pathology for lymph node enlargement was found in most of the cases. Hence FNAC is warranted in lymphadenopathy, as it is simple yet of great diagnostic value.

\section{REFERENCES}

1. Langlois S, Chryssidis S, editors. Orell \& Sterrett's Fine needle aspiration Cytology. 5th ed: Churchill livingstone; 2012. p28-37. Crossref

2. Dorothy L. Rosenthal, editor. Lymph Node Cytopathology. 1st ed: Springer; 2011.p 1-8.

3. Ruchi Khajuria, K. C. Goswami, K. Singh, V. K. Dubey: Pattern of Lymphadenopathy on Fine Needle Aspiration Cytology in Jammu. J K Science 2006;8:157-9.

4. Hirachand S, Lakhey M, Akhter J, Thapa B, Hirachand S: Evaluation of fine needle aspiration cytology of lymph nodes in Kathmandu Medical College, Teaching hospital; Kathmandu Univ Med J 2009;7:139-42.
5. Patel MM, Italiya SL, Patel RD, Dudhat RB, Kaptan KR, Baldwa VM. Role of Fine Needle Aspiration Cytology to Analyze Various Causes of Lymphadenopathy. Natl J Community Med 2013;4:48992.

6. Haque MA, Talukder SI. Evaluation of fine needle aspiration cytology (FNAC) of lymph node in Mymensingh. Mymensingh Med J 2003;12:33-5. Crossref

7. Kochhar AK, Duggal G, Singh K, Kochhar SK. Spectrum of cytological findings in patients with lymphadenopathy in rural population of South Haryana, India - experience in a tertiary care hospital. Internet J Pathol 2012;13:8.

8. Serrano Egea A, Martínez González MA, Pérez Barrios A, Alberti Masgrau N, de Agustín de Agustín P. Usefulness of light microscopy in lymph node fine needle aspiration biopsy. Acta Cytol 2002;46:3689. Crossref

9. Shrestha D, Thapa $\mathrm{p}$, Dahal M. Tuberculous and Nontuberculous Cervical Lymphadenitis: A clinical Review. Nepalese Journal of ENT Head \& Neck Surgery 2010;1:12-13.Crossref

10. Engzell U, Jacobsson PA, Singurdson A, Zajicek J. Aspiration biopsy of metastatic carcinoma in lymph nodes of neck. A review of 1101 consecutive cases. Acta Otolaryngol 1971;72:138-47. Crossref

11. Hajdu SI, Melamed MR. The diagnostic value of aspiration smears. Am J clin Pathol 1973;59:350-4. Crossref 